\title{
Investigation of structure formation processes at the hydration of modified gypsum binders and mortars
}

\author{
Vasili Korovyakov ${ }^{1}$, Anna Zaikina ${ }^{1}$, and Vadim Solovyov ${ }^{2, *}$ \\ ${ }^{1}$ Research Institute Mosstroy, Moscow, Russian Federation \\ ${ }^{2}$ Moscow state university of civil engineering, Yaroslavskoye shosse, 26, Moscow, Russia, 129337
}

\begin{abstract}
The results of investigations of structure formation processes of a mortar while hardening have been presented in the article. The results obtained indicate that during the period of structure formation and the heat release of solidifying composite gypsum binders and solutions, the heat release in hardening of composite gypsum binders (CGB) and modified gypsum mortars (MGM) proceeds at different rates, and is characterized, in some cases, by the rapid release of hydration heat. As studies have shown, modified gypsum binders and mortars, in order to avoid the appearance of structure defects, should contain setting-time additives, promoting to a decrease in the intensity of heat release and, as consequence, reducing risks of destructive processes. With a large amount of a setting-time retarder, hydration process may be disturbed, and that can be accompanied by following abnormalities (abundant bleeding, slow gain in strength, etc.). Significant heat release during hardening allows using the developed mortars even at negative temperatures, as also evidenced by the results of other researchers.
\end{abstract}

\section{Introduction}

The aim of the studies performed: the definition of regularities in the process of structure formation at hardening of multicomponent binders and mortars, depending on compositions, type of components and their nature.

Currently, the assessment of quality indices of construction mortars is made in accordance with Russian Standard GOST 28013-98 "Mortars. General specifications" and Russian Standard GOST 31377-2008 "Dry building levelling plaster mixtures based on gypsum binder. Specifications". The main parameters of the quality of a mortar mixture according to these standards are: flowability, water retention ability, sedimentation, compressive strength, density and frost resistance $[1,2]$.

Of great importance for the development of technological properties of plaster mortars is the knowledge of structure formation processes in a hardening mortar, especially a multicomponent one, which is composite gypsum binders and mortars based on them.

\footnotetext{
* Corresponding author: s_vadim_g@mail.ru
} 
One of the most effective finishing mortars is gypsum modified mortars $[3,4,5]$.

\section{Materials and mixture composition}

Studies have been conducted to determine the period of structure formation of gypsum systems and, accordingly, the patterns of structure formation with heat losses to the environment. For the studies, compositions consisting of a hemihydrate gypsum binder (GB) and an organomineral modifier were prepared [6 - 9].

As a gypsum binder the binder of grade G-7 BI, manufactured by the Peshelansky plant, in accordance with Russian Standard GOST 125-79, was used. The organomineral modifier was prepared from Portland cement of CEM I 42.5 N by Russian Standard GOST 311082003 of Volsky cement plant, microsilica (Russian Technical conditions 5743-04802495332-96 "Microsilica condensed", and C-3 superplasticizer based on naphthalene sulfonic acids according to Russian Technical conditions 6-36-0204229-625-90 "Plasticizer C-3".

\section{Results}

The process of structure formation while hardening of modified compositions consisting of a gypsum binder, a hydraulic component, various additives and modifiers, is of interest [10$12]$. In the present studies, the structure formation process was studied in terms of the kinetics of heat release while hardening of binders $[13,14,15,16]$.

The reactions of the interaction of hemihydrate calcium sulfate with water are exothermic, i.e. proceed with the release of heat. From a production point of view, it is important to know both the absolute amount of heat that can be released during the binder hydration, and the kinetics of heat release.

Figures $1-4$ show the kinetics of temperature change of solidifying systems. The analysis of curves showing changes in the temperature of mortars with a content of aggregate of $5 \%, 50 \%$, optimal composition, and without the addition of setting-time retarders in the systems showed the following:

- the composition with content of 5\% aggregate has the most intensive character of heat release. In the composition, the maximum temperature of $44.4{ }^{\circ} \mathrm{C}$ is reached after 24.5 minutes, with a treatment period of $9-15 \mathrm{~min}$;

- composition with content of 50\% aggregate (by weight) has a slightly less pronounced heat release $\left(43{ }^{\circ} \mathrm{C}\right.$ after 32.5 minutes of observation) with a mortar setting time of $8 \ldots 14$ minutes;

- a mortar of an optimal composition of 1:1 based on a modified gypsum binder and sand with $\mathrm{Mk}=2.0$ falls in between above compositions (the temperature is only $40.2{ }^{\circ} \mathrm{C}$ after 23 minutes of the initial formation of the structure of stone with its time terms only 4 7 minutes).

The kinetics of temperature changes in MGM compositions with a setting-time retarder in amount of $0.2 \%$ of the weight of MGB and the content of aggregate of various sizes is almost similar. 


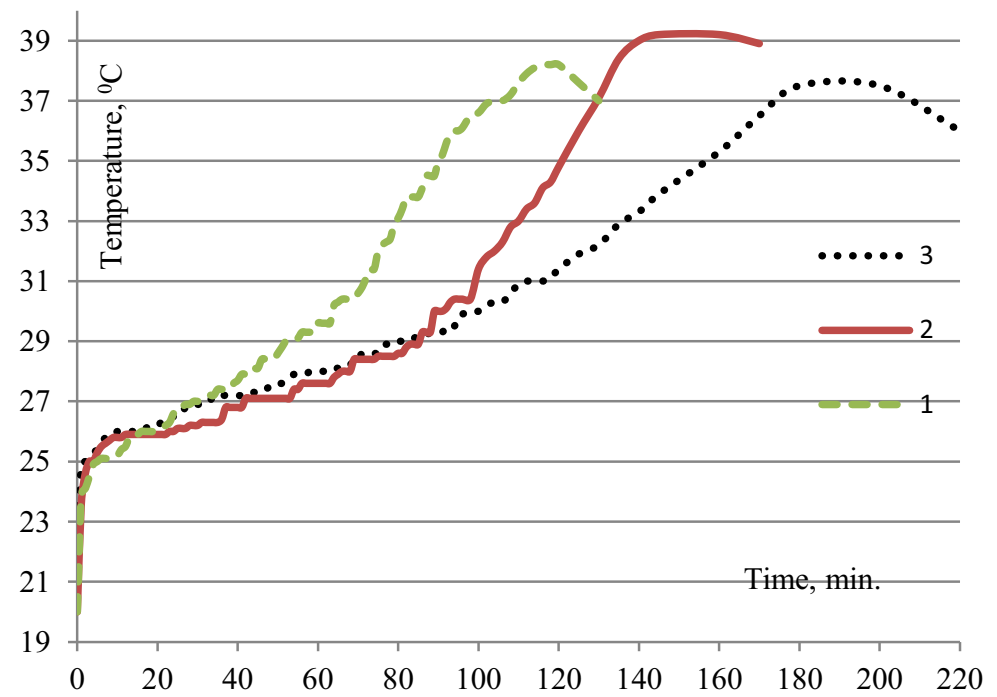

Fig. 1. Hardening behaviour of modified gypsum binder (MGB) with $0.2 \%$ retarder: 1 gypsum binder with $20 \%$ organomineral modifier; 2 - gypsum binder with $25 \%$ organomineral modifier; 3 - gypsum binder with $25 \%$ organomineral modifier.

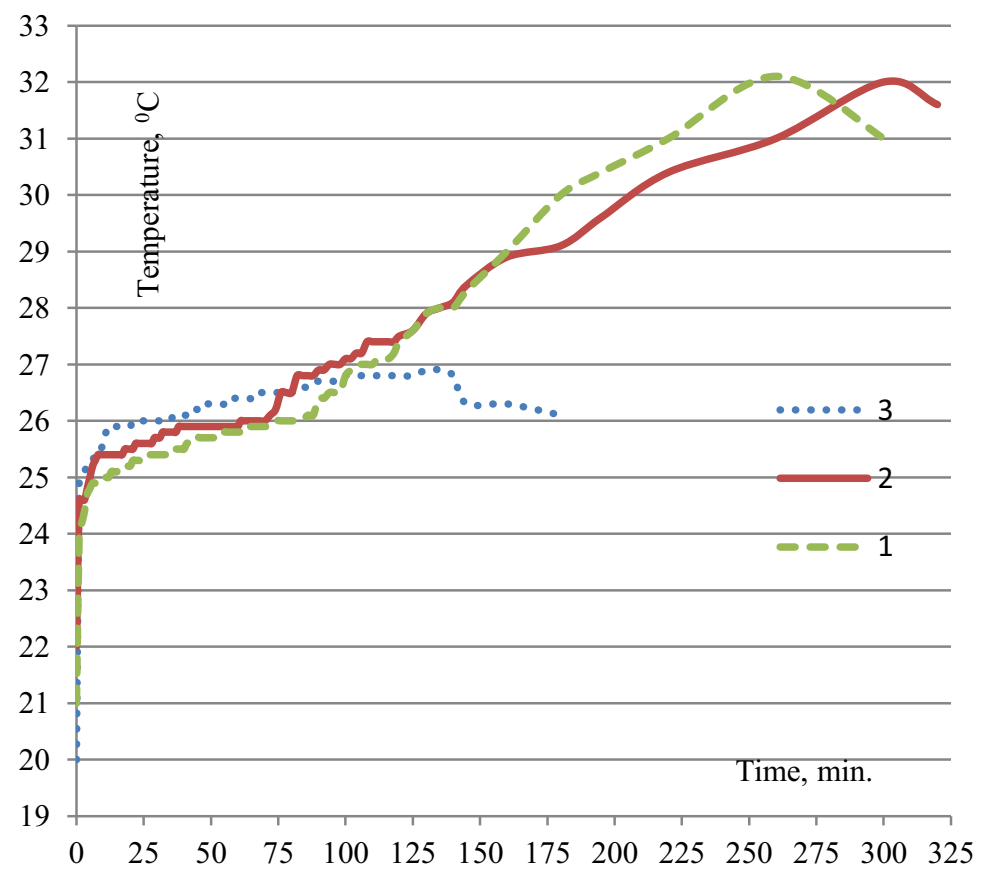

Fig.2. Hardening behaviour of modified gypsum binder (MGB) with $0.3 \%$ retarder: 1 gypsum binder with $20 \%$ organomineral modifier; 2 - gypsum binder with $25 \%$ organomineral modifier; 3 - gypsum binder with $25 \%$ organomineral modifier. 


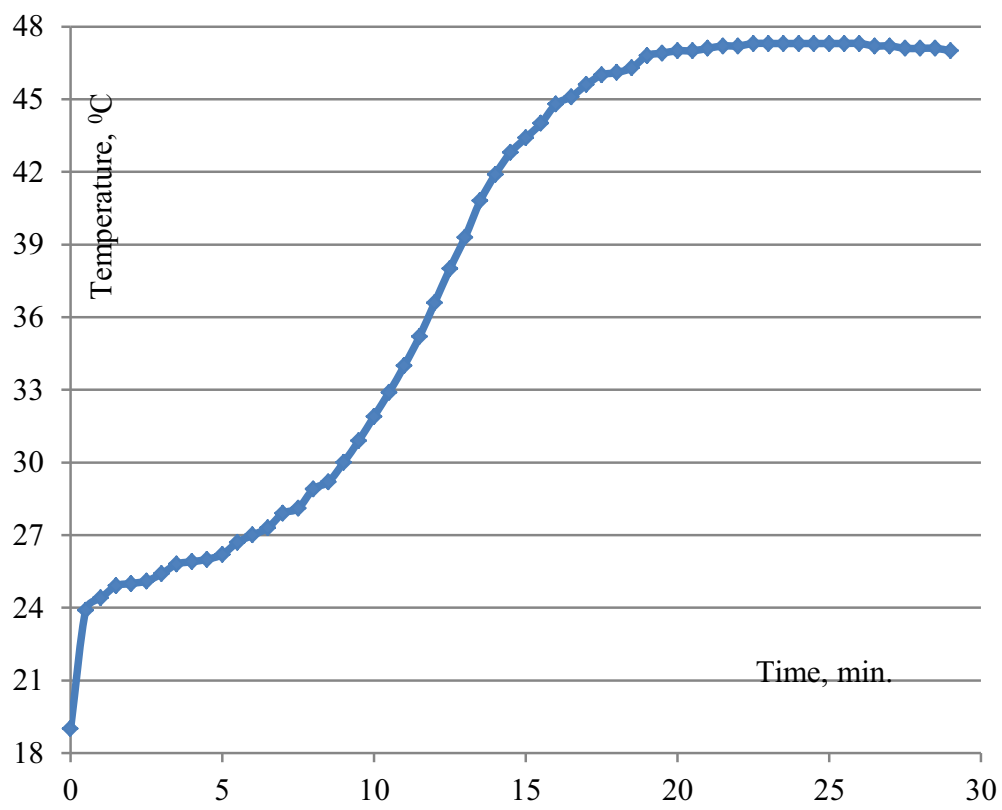

Fig. 3. Hardening behaviour of the optimal composition of modified gypsum binder (MGB).

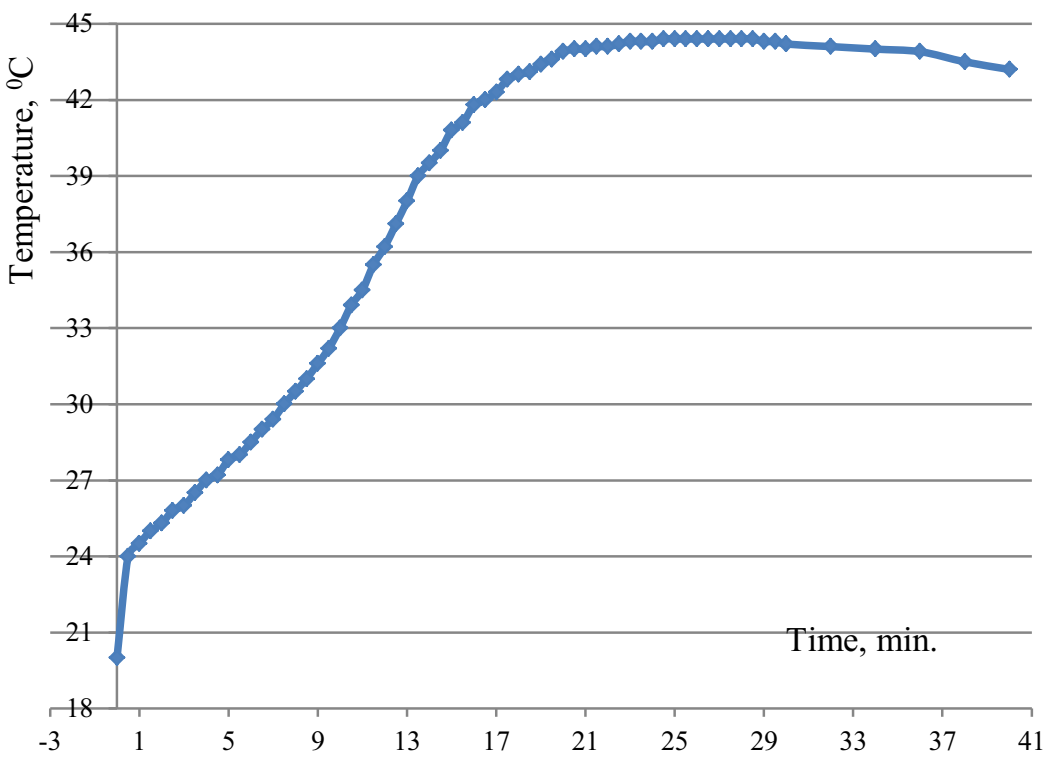

Fig. 4. Hardening behaviour of the optimal composition of modified gypsum mortar: binder + fine aggregate $(95+5 \%)$.

Hardening and structuring of the mortar is the most important stage determining the further quality of the solidified mortar. The control of this process is necessary both at the preparation stage and at the stage of application of the mortar mixture. As can be seen from the results obtained, the complex of technological factors (amount of additives introduced, ratio of components, size of the aggregates, etc.) affects the period of the structure 
formation and the heat release temperature of the solidifying composite gypsum binders and mortars.

\section{Conclusion}

Thus, analyzing the obtained data, the heat release process can develop at different rates and is characterized by the rapidly released hydration heat. In systems without regulation of the setting (hardening) time, a drastic increase in temperature is noted, therefore internal pressure and an emerging temperature gradient may arise (especially on massive surfaces treated). In addition, exothermic processes take place at the end of workability, and the structure may not reach the initial critical strength capable of withstanding internal tensile stresses when heated, the same effect can be observed in mortar systems with a filler, but without additives regulating the setting time. The main principle of the processes of normal structure formation (especially in the technological application) is provided by the expediency of using additives regulating the kinetics of hardening due to the formation (in given ranges) of hardly soluble and slightly dissociable compounds. As the studies have shown, the modified gypsum binders and mortars, in order to avoid the appearance of structure defects, should contain setting-time regulators that help to reduce the intensity of heat release and, as a consequence, reduce the risks of destructive processes.

Summarizing the above, it can be noted that the choice of the optimal composition of the mortar mixture is determined not only by solving the problems of obtaining a mortar with predetermined physical and mechanical properties, but also by effectively controlled processes of structure formation, which are the most important factor determining the further quality of the solidified mortar, as well as its workability. The control of these processes is necessary to define the viability of the mortar mixture, as well as the timing (age) of testing the solution and determining its moisture content. A significant rise in temperature makes it possible to apply the mortars developed at negative temperatures, too, as evidenced by the results of other researchers.

\section{References}

1 G. Severinova, Walls and facades (in Russian - Steny i fasady), 6, 45 (2006)

2 V. Korovyakov, Dry mixtures (in Russian - Suhie stroitelnye smesi), 1 (2007)

3 M. Muller, H. Fischer, Conductometric description of processes of interaction of calcium sulfate with water (Konduktometrische Beschreibung der Prozesse beim Kontakt mit Wasser von Calciumsulfaten). //SB. Gypsum, its study and application. - Kraskovo, 2005.

4 A. Adamtsevich, S. Pashkevich, A. Pustovgar, Magazine of Civil Engineering (in Russian - Inzhenerno-stroitelnyj zhurnal), 3 (2016)

5 V. Korovyakov, Russian chemical journal (in Russian - Rossijskij himicheskij zhurnal), 4 (2003)

6 Q. Yu, H. Brouwers, Cem. and Conc. Comp., 34, 9 (2012)

7 R. Magallanes-Rivera, C. Juarez-Alvarado, P. Valdez, J. Mendoza-Rangel, Cons. and Build. Mat, 37 (2012)

8 M. Singh, M. Garg, Cem. and Conc. Res., 23, 1 (1993).

9 A. Colak, Cem. and Conc. Comp., 22, 3 (2000)

10 V Soloviev, A. Eremin, D. Eliseev, A. Buryanov, Building materials (in Russian Stroitelnye materialy), 1-2 (2017)

11 E. Boldygeva, A. Buryanov, N. Galtseva, V. Soloviev, Building materials (in Russian - Stroitelnye materialy), 6 (2015) 
12 E. Boldygeva, Galtseva N., A. Buryanov, V. Petropavlovskaya, Journal of Modern problems of science and education (in Russian - Aktualnye problemy nauki i obrazovanija), 2, 71 (2013)

13 G. Vasconcelosa, P. Lourencoa, A. Camoesb, A. Martinsa, S. Cunha, Cem. and Conc. Comp., 58 (2015)

14 J. Escalante-García, M. Rios-Escobar, A. Gorokhovsky, A. Fuentes, Cem. and Conc. Comp., 30, 2 (2008)

15 M. Garg, A. Pundir, Cem. and Conc. Comp., 45 (2014)

16 V. Nilles, J. Plank, Cem. and Conc. Res., 42, 5 (2012) 